\title{
EVIDENCE OF POST-NATAL ENVIRONMENTAL INFLUENCE IN THE AETIOLOGY OF INFANTILE PYLORIC STENOSIS
}

\author{
BY \\ THOMAS McKEOWN, BRIAN MacMAHON* and R. G. RECORD \\ From the Department of Social Medicine, University of Birmingham
}

(RECEIVED FOR PUBLICATION JANUARY 25, 1952)

The fact that the risk of infantile pyloric stenosis is related to position in family suggests that the environment influences the incidence of the disease, since there is no reason to suppose that inherited differences are affected by birth order, while examples of both pre-natal and post-natal environmental effects associated with birth order are well known (McKeown, MacMahon and Record, 1951a and b). The observation that size of the pyloric tumour is highly correlated with age at operation (McKeown et al., 1951c) supports the view that the tumour develops after birth, but does not, of course, exclude the possibility that the environmental influence (suggested by the association of incidence with birth rank) is exerted before birth. The present communication provides evidence that this environmental effect is post-natal by showing first that immediately after birth the disease is equally common in all birth ranks (it is not until about the third week that the incidence in firstborn is significantly raised), and secondly that symptoms appear earlier in domiciliary than in hospital births.

\section{Risk of Pyloric Stenosis Related to Age and Birth Rank}

For all patients $(1,059)$ treated for pyloric stenosis at the Birmingham Children's Hospital in the years 1940-51 we have recorded from case notes the age at onset of symptoms and birth rank. Of these children, 680 were born to Birmingham mothers and 379 to mothers resident outside the city. It should be said at once that 'age at onset of symptoms' is not an entirely satisfactory observation, first because onset is by no means invariably sharp, and may be difficult to identify from the common regurgitation of food by young infants, and secondly, because any such record taken from the mother's statement when the child is admitted to hospital is subject to error. But to have any bearing on the treatment which follows, the errors would have to be selective in respect of birth rank, and we can think of no reason why they should be.

Table 1 shows that the proportions of first, second and third and later births among affected

TABLE 1

Percentage distribution by Birth Rank according to Age AT ONSET OF SYMPTOMS *

\begin{tabular}{c|c|c|c|c|c|c|c|c|c}
\hline $\begin{array}{c}\text { Birth } \\
\text { Rank }\end{array}$ & $0-6$ & $7-13$ & $14-20$ & $21-27$ & $28-34$ & $35-41$ & $\begin{array}{c}42 \\
\text { and } \\
\text { over }\end{array}$ & Total \\
\hline 1 & 44 & 42 & 53 & 58 & 53 & 55 & 52 & $52(540)$ \\
\hline 2 & 29 & 36 & 29 & 22 & 26 & 28 & 28 & $27(281)$ \\
\hline $\begin{array}{c}\text { and } \\
\text { over }\end{array}$ & 27 & 22 & 18 & 20 & 21 & 17 & 20 & $21(212)$ \\
\hline Total & $\begin{array}{c}100 \\
(96)\end{array}$ & $\begin{array}{c}100 \\
(97)\end{array}$ & $\begin{array}{c}100 \\
(218)\end{array}$ & $\begin{array}{l}100 \\
(241)\end{array}$ & $\begin{array}{l}100 \\
(187)\end{array}$ & $\begin{array}{c}100 \\
(82)\end{array}$ & $\begin{array}{c}100 \\
(112)\end{array}$ & $100(1,033)$ \\
\hline
\end{tabular}

* The table is based on patients treated for pyloric stenosis at the Birmingham Children's Hospital between January, 1940, and October, 1951. In 26 of 1,059 cases records were incomplete.

children differ according to their age at the onset of symptoms. The difference is most marked between the first fortnight and the later weeks which are compared in Table 2. Thus the percentage of firstborn among children whose symptoms appeared within two weeks of birth is $43 \cdot 0$, much lower than among children whose symptoms began after the first fortnight $(54 \cdot 4)$. The difference between these

TABLE 2

Percentage Distribution by Birth Rank of Patients with SYMPTOMS BEFORE OR AFTER THE FOURTEENTH DAY

\begin{tabular}{c|c|c}
\hline Birth Rank & Age at Onset of Symptoms (days) \\
\hline 1 & $0-13$ & 14 and over \\
\hline 2 & $43 \cdot 0$ & $54 \cdot 4$ \\
\hline 3 and over & $32 \cdot 6$ & $26 \cdot 0$ \\
\hline Total & $24 \cdot 4$ & $19 \cdot 6$ \\
\hline $\begin{array}{c}100 \\
(193)\end{array}$ & $\begin{array}{c}100 \\
(840)\end{array}$
\end{tabular}

* In receipt of a grant from the Medical Research Council. 
two percentages $(11 \cdot 4)$ is significant (standard error $\pm 4 \cdot 0$ ). This suggests that the relative risk of pyloric stenosis in first births compared with later births is lowest immediately after birth, and increases at about the third week. Indeed, of children whose symptoms appear within the first two weeks of life the proportions in each birth rank (see Table 2) are probably not very different from that of the general population of births from which they are drawn, but to confirm this impression we should require to know the distribution by birth rank of the related population of unaffected births. A rough comparison with an estimate based on the Registrar-General's figures for the region Midland I, 1942-49 (Table 3) suggests that immediately after

TABLE 3

Percentage Distribution by Birth Rank of Patients with SYMPTOMS BEFORE THE FOURTEENTH DAY AND OF ALL LegITIMATE BIRTHS IN THE REgION MIDLAND I

\begin{tabular}{c|c|c}
\hline Birth Rank & $\begin{array}{c}\text { Patients with } \\
\text { Symptoms } \\
\text { Twithin }\end{array}$ & $\begin{array}{c}\text { Estimated Distribu- } \\
\text { tion of All Births in } \\
\text { Midland Region I, } \\
1942-49^{*}\end{array}$ \\
\hline 1 & $43 \cdot 0$ & $41 \cdot 1$ \\
\hline 2 & $32 \cdot 6$ & $29 \cdot 1$ \\
\hline 3 and over & $24 \cdot 4$ & $29 \cdot 8$ \\
\hline Total & 100 \\
$(193)$ & $\begin{array}{c}100 \\
(745,691)\end{array}$ \\
\hline
\end{tabular}

- Based on the Registrar-General's statistics. $\chi^{2}=2 \cdot 96, \quad \mathrm{n}=2, \quad 0 \cdot 2<\mathrm{p}<0 \cdot 3$.

birth pyloric stenosis may be no more common in first than in later births. Of course we cannot be confident about the validity of a comparison with all births in the region. What is required is the incidence of pyloric stenosis in each birth rank, and this can be given for Birmingham live births notified in the years 1942-49. For this period, from an earlier enquiry (MacMahon, Record and McKeown, 1951), we have fairly reliable estimates of the numbers of Birmingham children (affected and unaffected) in each birth rank, which have been used to calculate the incidence of new cases of pyloric stenosis in first, second and third and later births, according to age at the onset of symptoms (Table 4). The data indicate that there is no definite association between the incidence of pyloric stenosis and birth rank until about the third week of life, and the incidence in firstborn rises sharply in the third and fourth weeks. In Fig. 1 the incidence in each birth rank is shown as a cumulative total.

TABLE 4

Incidence (per 1,000 related Live Births) of Pyloric Stenosis RELATED TO Age AND BIRTH RANK*

\begin{tabular}{c|c|c|c|c|c|c|c|c}
\hline $\begin{array}{l}\text { Birth } \\
\text { Rank }\end{array}$ & $0-6$ & $7-13$ & $14-20$ & $21-27$ & $28-34$ & $\begin{array}{c}35 \\
\text { and } \\
\text { over }\end{array}$ & $\begin{array}{c}\text { Un- } \\
\text { known }\end{array}$ & Total \\
\hline 1 & 0.26 & 0.31 & 1.00 & $1 \cdot 10$ & 0.64 & 0.72 & 0.25 & $4 \cdot 28(244)$ \\
\hline 2 & 0.24 & 0.26 & 0.50 & 0.52 & 0.54 & 0.62 & 0.10 & $2 \cdot 77(139)$ \\
\hline $\begin{array}{c}3 \text { and } \\
\text { over }\end{array}$ & 0.28 & 0.14 & 0.31 & 0.42 & 0.26 & 0.31 & 0.16 & 1.88 (95) \\
\hline Total & 0.26 & 0.24 & 0.62 & 0.70 & 0.48 & 0.56 & 0.17 & $3.03(478)$ \\
\hline
\end{tabular}

- The table is based on Birmingham City cases treated in hospitals during the period 1942-49.

It should be noted that although the incidence in firstborn is undoubtedly raised relative to later births in all subsequent weeks for which the number of cases is large enough to justify examination, from the end of the third week the estimates of incidence may not measure accurately the increased risks to which first births are exposed. The reason is as follows. The incidence of pyloric stenosis is approximately the same in all birth ranks during the first two weeks, and hence it is permissible to regard the raised incidence of onset of the disease in first births in the third week as a reliable measure of increased risk. But the fact that relatively more first births have been affected by the end of the



FIG. 1.-Cumulative incidence of pyloric stenosis by birth rank at weekly intervals after birth.

The figure is based on Birmingham city cases treated in hospitals during the period 1942-49. 
third week means that fewer susceptible first births remain unaffected at the beginning of the fourth week. (The possibility that sqme children are more susceptible than others is, of course, entirely compatible with our reservations (McKeown et al., 1951b) about specific inheritance in pyloric stenosis). Hence the incidence of affected among firstborn may somewhat understate the risk compared with the risk to later births in the fourth week. The same considerations apply in all subsequent weeks. This means that the decreased incidence of new cases among first births after the third week cannot confidently be interpreted to mean that the environment is becoming more favourable; in any case it clearly remains unfavourable as compared with the environment of second and later births, and may be relatively more unfavourable than the figures indicate.

\section{Age at Onset of Symptoms of Children with Pyloric Stenosis Born in Hospital and at Home}

The data presented in Tables 1-4 are consistent with the view that the post-natal environment is responsible for the increased risk of pyloric stenosis in first as compared with later births. This environmental influence must be exerted almost immediately after birth, for its effects are evident from the raised incidence of the disease in firstborn in the third week. Since the environment to which children are exposed in the first two weeks of life is related to their place of birth, we now enquire whether there are differences between hospital and domiciliary births (1) in incidence of pyloric stenosis and (2) in age of patients at onset of symptoms.

Unfortunately we cannot give separate figures of incidence for hospital and domiciliary births, because the relative numbers of births at risk are unknown for several of the years under consideration. But in Birmingham a little less than half of all births are delivered in hospital, and in those years which we have examined about half the children with pyloric stenosis were hospital births. We conclude that the incidence of the disease is certainly no lower in hospital than in domiciliary births. Of course, it must be remembered that the proportion of first births, and hence the expected incidence of pyloric stenosis, is higher in hospital deliveries, and a satisfactory comparison cannot be made in the absence of precise figures.

Age at onset of symptoms is, however, quite different in the two cases. The requisite informa- tion is given in Table 5 for 782 of the 1,033 cases shown in Table 1 (110 patients were born in nursing homes, and in 141 cases place of birth is unknown). In general, symptoms begin earlier if children arecô born at home: thus the proportion of patients whose? symptoms appeared within three weeks of birth is considerably higher for domiciliary $(46.6 \%)$ than for hospital births $(31 \cdot 3 \%)$.

It is conceivable that the difference in frequency of onset in the first two weeks might be explained by the fact that mothers whose children are born at home recall the early symptoms more vividly. But the higher incidence in domiciliary births is shown in the third week, by which time children born in hospital have returned to their homes. We have also compared hospital and domiciliary cases in respect of age at operation, since the date of operation is recorded in case notes and is therefore an objective figure. The proportion of patients brought to operation within the first four weeks is $21 \cdot 2 \%$ for domiciliary births, and $15 \cdot 8 \%$ for hospital births (difference $5 \cdot 4 \pm 2 \cdot 9$ ).

Before concluding that the difference in age at onset of symptoms supports the view that the postnatal environment influences the disease, we must consider the possibility that it merely reflects the well-known difference in parity composition of hospital and domiciliary births, since we have shown that age at onset of symptoms is related to birth rank. In Table 6 (see also Fig. 2) the comparison of age at onset is confined to first births; the results are entirely consistent with those recorded in Table 5 for all births. We conclude that the 
TABLE 5

Percentage Distribution by Age at Onset of Symptoms of Children with Pyloric Stenosis Born in Hospital and at Home

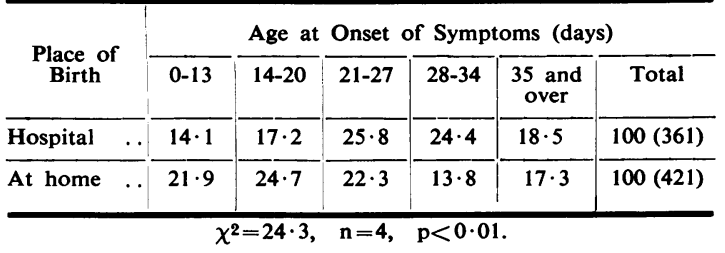

TABLE 6

Percentage Distribution by Age at Onset of Symptoms of Firstborn Children WITH Pyloric Stenosis BorN IN Hospital AND AT HOME

\begin{tabular}{c|c|c|c|c|c|c}
\hline \multirow{2}{*}{$\begin{array}{c}\text { Place of } \\
\text { Birth }\end{array}$} & \multicolumn{5}{|c|}{ Age at Onset of Symptoms (days) } \\
\cline { 2 - 6 } & $0-13$ & $14-20$ & $21-27$ & $28-34$ & $\begin{array}{c}35 \text { and } \\
\text { over }\end{array}$ & Total \\
\hline Hospital & $11 \cdot 6$ & $18 \cdot 2$ & $29 \cdot 8$ & $23 \cdot 1$ & $17 \cdot 3$ & $100(225)$ \\
\hline At home & $17 \cdot 8$ & $27 \cdot 8$ & $21 \cdot 9$ & $13 \cdot 0$ & $19 \cdot 5$ & $100(169)$ \\
\hline & $\chi^{2}=14 \cdot 3$, & $n=4$, & p $<0.01$.
\end{tabular}

earlier appearance of symptoms in children born at home is attributable to the post-natal environment.

\section{Data from Two Liverpool Hospitals}

As a check on the results obtained in Birmingham, we have attempted to record similar information in another city, and we are greatly indebted to the staffs of the Alder Hey and Royal Liverpool Children's Hospitals for giving us access to records of 327 cases. Table 7 gives birth rank in relation to age at onset of symptoms for the 269 patients for whom the data were complete. Numbers are not large enough to give significant results (as in Table 2), but the increase in the proportion of firstborn from the second week is consistent with the trend recorded on Birmingham patients in Table 1. In Liverpool the proportion of births delivered in hospital is considerably higher than in Birmingham, and age at onset of symptoms might therefore be expected to be a little later.

TABLE 7

Percentage Distribution by Birth Rank According to Age AT ONSET OF SYMPTOMS

\begin{tabular}{|c|c|c|c|c|c|c|c|}
\hline \multirow{2}{*}{$\begin{array}{l}\text { Birth } \\
\text { Rank }\end{array}$} & \multicolumn{7}{|c|}{ Age at Onset of Symptoms (days) } \\
\hline & $0-6$ & $7-13$ & $14-20$ & $21-27$ & $28-34$ & $\begin{array}{l}35 \text { and } \\
\text { over }\end{array}$ & Total \\
\hline 1 & 35 & 46 & 44 & 47 & 53 & 42 & 46 (123) \\
\hline 2 & 41 & 42 & 24 & 18 & 25 & 31 & $27(74)$ \\
\hline $\begin{array}{l}3 \text { and } \\
\text { over }\end{array}$ & 24 & 12 & 32 & 35 & 22 & 27 & $27(72)$ \\
\hline Total & $\begin{array}{l}100 \\
(17)\end{array}$ & $\begin{array}{l}100 \\
(24)\end{array}$ & $\begin{array}{l}100 \\
(54)\end{array}$ & $\begin{array}{l}100 \\
(51)\end{array}$ & $\begin{array}{l}100 \\
(59)\end{array}$ & $\begin{array}{l}100 \\
(64)\end{array}$ & $100(269)$ \\
\hline
\end{tabular}

* The table is based on patients treated at the Alder Hey Hospital and the Royal Liverpool Children's Hospital in the years 1942-51.

\section{Discussion}

For reasons stated elsewhere (McKeown et al., 1951b) and summarized in the opening paragraph of this paper, we regard the increased incidence of pyloric stenosis in first births as evidence of environmental influence in the aetiology of the disease. Our purpose here has been to enquire whether this influence is exerted before or after birth, and we give two reasons for believing it to be post-natal. (1) The disease is about equally common in all birth ranks until the third week of life. (2) The onset of symptoms is earlier in domiciliary than in hospital births.

It may be objected that manifestation of a pre-natal environmental influence might conceivably be delayed until a few weeks after birth. This explanation would be more impressive if the influence were manifested on the earliest cases. Moreover, it would not account for the difference in age at onset of symptoms between domiciliary and hospital births which can hardly be explained otherwise than as a post-natal environmental effect.

If these views are correct it is of considerable practical importance to consider the nature of the environmental influence, upon which the possibility of future control of the disease may depend. At present we have no direct evidence, but the data suggest that the unfavourable environment exerts its effect almost from birth on patients born at home, and after their return home on patients born in hospital.

Finally, the fact that the incidence of cases which arise in the first two weeks of life is unrelated to birth rank suggests that they are different aetiologically from later cases. For 79 patients whose symptoms appeared within two weeks of birth we have therefore examined $(a)$ the incidence of pyloric stenosis in sibs, $(b)$ the incidence of pyloric stenosis in cousins and $(c)$ the incidence of consanguinity of parents. Numbers are, of course, small, but the results are the same as those obtained when all patients were considered (McKeown et al., 1951b); that is to say we have no evidence of specific inheritance in the early cases.

\section{Summary}

Evidence of post-natal environmental influence in the aetiology of pyloric stenosis is provided by an investigation of 1,059 patients treated at the Birmingham Children's Hospital in the years 1940-51.

Immediately after birth the disease is equally common in all birth ranks, but the incidence in first births rises sharply in the third and fourth weeks 
and remains raised relative to later births in all subsequent weeks examined. The percentage of firstborn among children whose symptoms appeared within two weeks of birth was $43 \cdot 0$, much lower than among children whose symptoms began after the first fortnight $(54 \cdot 4)$.

The onset of symptoms is earlier in domiciliary than in hospital births. Thus, symptoms appeared within three weeks of birth in $46.6 \%$ of children born at home, and in $31.3 \%$ of children born in hospital. This difference is not explained by differences in parity composition of hospital and domiciliary births, and is even greater when first births are considered separately.

We are indebted to Professor J. M. Smellie and the staff of the Birmingham Children's Hospital, and to Professor N. B. Capon and the staffs of the Alder Hey and Royal Liverpool Children's Hospitals, for permission to use their records and for the facilities made available to us.

McKeown, T., MacMahon, B. and Record, R. G. (1951a). Ann. Eugen., Camb., 16, 249.

二- 二-, 二- (1951b). Ibid., 16, 260.

MacMahon, B. Record, R. G., and McKeown, T. (1951). Brit. J. soc. Med., 5, 185 . 